\title{
OPERATIONS MODELING AND ANALYSIS OF OPEN PIT COPPER MINING USING GPS TRACKING DATA
}

\author{
Yifei Tan \\ Chuo Gakuin University \\ Faculty of Commerce \\ 451 Kujike \\ Abiko, Chiba, 270-1196, JAPAN \\ Kanna Miwa \\ Nagoya Gakuin University \\ Faculty of Commerce \\ 1-25 Atsutanishimachi, Atsuta-ku \\ Nagoya, Aichi, 456-8612, JAPAN
}

\author{
Undram Chinbat \\ National University of Mongolia \\ School of Economic Studies \\ Baga Toiruu 4, Sukhbaatar District \\ Ulaanbaatar, 210646, MONGOLIA
}

\begin{abstract}
Open pit copper mining plants usually comprise two major components, the open pit mining operation and the copper ore enrichment plant. An open pit copper mine is an excavation or graze made into the surface of the ground for the purpose of extracting ore. A series of data obtained by a transportation control system with GPS (Global Positioning System) technology is utilized to perform the simulation. Operations in the mine are based on a mining plan and must be optimized because the transportation costs are expensive. In this paper, procedures are proposed to obtain an optimized number of trucks and to estimate the maximum mining capacity at an open copper pit. Then, the creation of a truck dispatching control table for meeting the maximum mining capacity is demonstrated by performing a simulation.
\end{abstract}

\section{INTRODUCTION}

Mining operations are the beginning of a supply chain that comprises raw material extraction, raw material processing, fabrication, wholesale, retail, and, ultimately, consumption. At present, Mongolian economic growth is highly supported by the mining industry. In 2007, according to the Mongolian Statistical Yearbook, Mongolia's GDP grew by 8.4 percent overall, and the mining sector grew by 2.7 percent. High international gold and copper prices have led to new mine exploitation and increased production in this sector (Chinbat and Takakuwa 2009). The mining industry is required to respond flexibly to trends in world market demands. Companies must improve their operations in the mining and transportation of mined products.

This study applies computer simulations to support operations management in open pit mining. A simulation model was constructed and carried out to evaluate the current state of operations for a company by utilizing GPS (Global Positioning System) tracking data. Then, an analysis was performed specifically on the number of dump trucks in relationship to the maximum mining capacity. Additionally, a sim- 
ulation model was used to create a truck dispatching table in accordance with the maximum mining capacity.

\section{LITERATURE REVIEW}

There are two general approaches to mining: one method is known as open pit (i.e., surface) mining, and the other method is called underground mining. Surface mining, which can be used when the ore is close to the surface of the Earth, is an older and more productive method than underground mining. Despite the relatively lower fixed infrastructure cost of an open pit mine, surface mines necessitate a significant extraction of waste. A mine becomes cost prohibitive to operate when the ratio of the extracted waste to ore becomes too high, when the waste storage space is insufficient, when the pit walls fail, or when the environmental considerations outweigh the extraction benefits. When these issues are potential realities, underground mining is the method of choice (Newman et al. 2011).

The problems that face the mining industry are growing in both size and complexity. Production is dependent on geological position of the ore body and technology for extraction, which involves the use of expensive capital equipments. Simulations can be used to aid management in making decisions related to daily production and capital expenditures. Simulation based optimization has been performed in various cases in the mining industry, both for the open pit and underground mines. Kazakidis and Scoble (2003) stated that underground mines often face uncertainties in production planning; these uncertainties are associated with a variety of issues, such as the grade distribution, ground conditions, equipment reliability, infrastructure needs and the extraction method performance. Despite the best planning efforts, such operating uncertainty must be counter-balanced by the integration of a contingency plan to enhance flexibility in mining plants. Simulation models of an operations and materials handling system for an underground coal mine have been proposed to identify the bottleneck of a conveyance system to identify more efficient mining and conveyance methods (Miwa and Takakuwa 2011). Simulation based optimization was done by Chinbat and Takakuwa (2008) in an open pit mine Six sigma project to define, measure, analyze and improve the mining and enrichment processes. Another case study was performed to determine suitable numbers of drilling engineers and workers based on the open pit mine process (Chinbat and Takakuwa 2009).

Several studies related to open pit mining have been conducted on the operations and associated transportation systems. Bauer and Calder (1973) noted the need for realistic working models for the complexity of modern open pit load-haul-dump systems. Nenonen et al. (1981) studied an interactive computer model of truck/shovel operations in an open pit copper mine. Qing-Xia (1982) studied a computer simulation program of drill rigs and shovel operations in open pit mines. Truck haulage is the most common means of moving ore/waste in open pit mining operations, but it is usually the most expensive unit of operation in a truck-shovel mining system (Kolojna et al. 1993).

Burt et al. (2005) conducted a critical analysis of the various models used for surface mining operations, identifying important constraints and suitable objectives for an equipment selection model. They used a new mixed integer linear programming model that incorporates a linear approximation of the cost function. Fioroni et al. (2008) have proposed concurrent simulation and optimization models to achieve a feasible, reliable and accurate solution to the analysis and generation of a short-term planning schedule. Ercelebi and Bascetin (2009) studied shovel and truck operation models and optimization approaches for the allocation and dispatching of trucks under various operating conditions. They used closed queuing network theory for the allocation of trucks and linear programming (LP) for the purpose of dispatching trucks to shovels. Boland et al. (2009) proposed LP-based disaggregation approaches to solve a production scheduling problem regarding open pit mining. Subtil et al. (2011) proposed a multistage approach for dynamic truck dispatching in real open pit mine environments; the implementation was achieved with a commercial software package.

Additionally, GPS has been used to collecting data in real-time for simulation of heavy construction operations (Song et al. 2008). Navon and Shpatnitsky (2005) had developed a model to control road con- 
struction project by using GPS for measuring the locations of construction equipment. Biles and Bilbrey (2004) have used GPS data for a simulation model of an inland waterway system.

\section{AN OPEN PIT MINING OPERATION}

\subsection{The Mining Company}

This study was conducted on one of the largest ore mining and ore processing companies in Asia. The mine and factory are located in Mongolia and have been in operation since 1978. At present, the factory processes 25 million tons of ore per year and produces over 530 thousand tons of copper concentrate and 3.0 thousand tons of molybdenum concentrate annually. Because of the factory's confidentiality requirements, we refer to the factory in this study as company "A."

Recently, in response to turmoil related to the global currency and financial markets, the price of copper has fluctuated dramatically. To increase the competitiveness of company " $A$ " and to make the company flexible in its ability to respond to demands and trends in the international price of copper, it is important to improve the excavation and production systems. The following case study is part of a wider joint research project with company "A," which has the goal of improving the efficiency of the operations of mining and transportation in an open pit mine and in an ore enrichment plant. Simulations can help mining project managers to understand the behavior of the system and to optimize the system through various strategies by providing a visual and dynamic description (Chinbat and Takakuwa 2009). To support operations management in company "A," the computer simulation technique is applied.

\subsection{Description of an Open Pit Mining Operation}

Similar to most mining plants, the production process of company "A" consists of two major components, the open pit mine and the copper ore enrichment plant. An open pit mine is an excavation or graze made into the surface of the ground for the purpose of extracting ore, also known as open-cast mining or opencut mining.

The contents of copper and molybdenum have changed since the mine began its operations. Over the course of years of mining, the content of copper has gradually decreased. Additionally, in this open pit mine, the contents of copper and molybdenum vary according to the altitude of the specific mining location. Specifically, the content of copper at low-altitude mining points, at which there has been deep digging, is lower. However, from the perspective of operational management, to preserve the product quality as well as to maintain a stable throughput, it is desirable that the content of copper in the ore is approximately stable. In this context, before feeding the ore into the enrichment process, it is necessary to mix the ore to yield an initially high copper and low ore content. Therefore, when creating a mining plan in accordance with a production plan, it is necessary to plan for both ores containing a low copper content and a higher copper content. In company "A", a plan for the mining site is developed by the geologist group section. Additionally, it is difficult to determine the best mining positions by considering the required percentage of copper and molybdenum contents required to meet the operations planning of a successful refinery.

A simplified process map of open pit mine in company "A" is shown in Figure 1. As seen in the figure, in this open pit mining operation, the drilling work is performed based on the mining plan. An explosion process is performed once every fifth day of the week. The drilling work is halted during the explosion process because of safety regulations. This process is expected to satisfy the following raw material demands of the copper enrichment plant. The detonated ore and soil will be loaded onto 130-ton dump trucks by one excavator for each feature. In company "A", there are 24 dump trucks, and all of the trucks can be used to transport either the ore or the soil from the mining points to the enrichment plant or to the disposal hills, respectively, in accordance with the instructions provided from the operation center. There are 13 soil disposal locations (hills) around the location of open pit mining. At the soil disposal locations, the soil is spread over the ground using a bulldozer to recover the environment. In the enrichment plant, 
there are two ore feeding entrances. When the ore is transported to the enrichment plant, the ore will then be fed to an ore feeding entrance according to the size (the diameter) of the ore; the concentrating processes are then performed inside the plant. Some of the operating parameters in this open pit mine are listed in Table 1. In Table 1, the parameters of some measures are briefly indicated in averaged values.

\section{DATA AND SIMULATION MODELS}

\subsection{The Scope and Purpose of This Study}

The main purposes of this study on company " $\mathrm{A}$ " are to improve the factory production system and mining and to allow the system to flexibly respond to the demands and trends in the international price of copper. The first step toward this goal is the investigation and evaluation of the current state (As-Is) of the mining and factory production processes in company "A". Subsequently, the problems are identified, and

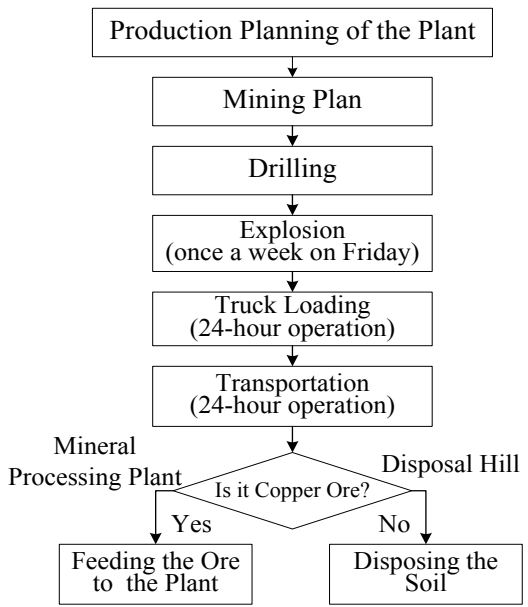

Figure 1: The simplified process map for open pit mining

Table 1: The list of the open pit mining operation parameters

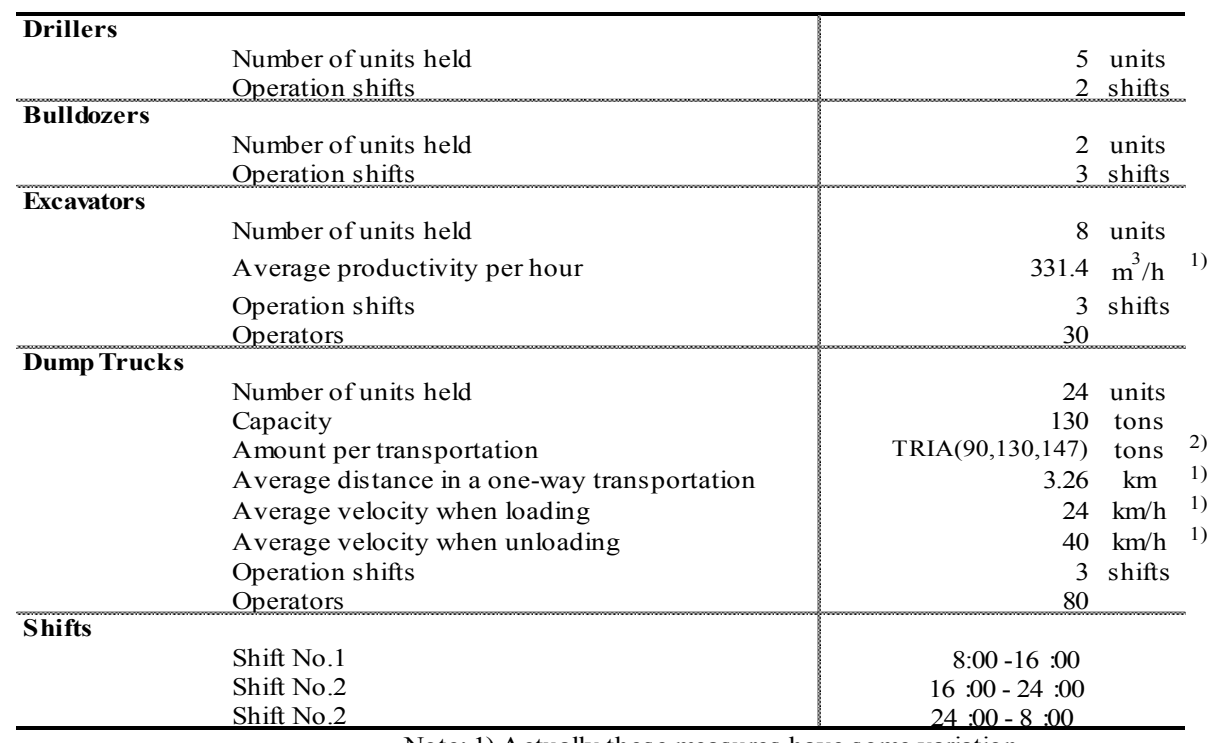

Note: 1) Actually these measures have some variation.

2) TRIA indicates a triangular distribution. 
an improvement plan (To-Be) will be devised. As explained previously, the mine plan is developed to keep with the production plan of the factory. Therefore, before carrying out a production plan for the enrichment plant, it is first necessary to determine the maximum mining capacity of the open pit. The mining capacity refers to the total amount of materials such as the waste and the ore that can be mined (Ramazan and Dimitrakopoulos 2004). As a starting point for this joint research project, we set the objectives of this study to the following three points (additionally, the scope of the study is limited to open pit mining):

- To understand and evaluate the current state (As-Is) of the open pit mining operation;

- To propose an improvement plan (To-Be) based on the evaluation of As-Is; and

- To estimate the maximum mining capacity of the open pit.

\subsection{The Parameters and the Construction of the Simulation Model}

Simulation involves designing a model of a real system and then conducting experiments with the model for the purpose of understanding the behavior of the system and/or evaluating various strategies for the operation of the system (Shannon 1998). In this study, to achieve the above-mentioned research objectives, a simulation technique is adopted. The simulation model is programmed in Arena (Kelton, et al. 2010 ) and is then overlaid on a scaled mine layout. A few years ago, company "A" introduced a mining transportation control system that utilizes GPS technology. The GPS tracking data and other associated information are used to update the simulation in 1-minute intervals; the important parameters, such as the truck location, the fuel level in the tank, and the load weight, are shown on the open pit map. At the designated mining site, blasting is performed in one-week intervals (on Fridays). Hence, the simulation models are constructed from the operating data collected over the course of one week. Figure 2 shows the sample historical transportation data used in this study; the data were extracted from the database of the information system. Table 2 shows an excavator plan for one week. Table 3 shows an example of historic excavation data for a given week. These data were input into the simulation model as part of the simulation parameters.

The first step in constructing the As-Is simulation model is to understand the current state (As-Is) of operations. Subsequently, the As-Is model is utilized as the basis for experimental analysis. The output from the As-Is model is then analyzed to determine the problems and the potential bottlenecks. An alternative analysis based on the results from the As-Is model is devised, and the To-Be model is then built. Finally, the To-Be model is applied, and the effect of any improvements is investigated. Moreover, to estimate the maximum mining capacity of company "A," an experimental model for capacity testing must also be constructed. A screen image for running the As-Is simulation model is shown in Figure 3.

\begin{tabular}{|c|c|c|c|c|c|c|c|c|c|c|}
\hline 4 & A & $B$ & $\mathrm{E}$ & $\mathrm{H}$ & I & J & K & L & M & $\mathrm{N}$ \\
\hline 4 & Truck No & Time Laoding & Time Unloading & $\begin{array}{c}\text { Transit Time } \\
\text { (min.) }\end{array}$ & $\begin{array}{l}\text { Weight } \\
\text { (tons) }-\end{array}$ & $\begin{array}{c}\text { Distance } \\
(\mathbf{k m})\end{array}$ & $\begin{array}{c}\text { Averaged } \\
\text { Speed (km/h) } \\
\end{array}$ & $\begin{array}{c}\text { Excavator } \\
\text { No. } \\
\end{array}$ & $\begin{array}{l}\text { Unloading } \\
\text { Location }\end{array}$ & $\begin{array}{c}\text { Time for } \\
\text { Unloading (min.) } \\
\end{array}$ \\
\hline 5 & 62 & $2011 / 12 / 10: 19$ & $2011 / 12 / 10: 31$ & 11.6 & 111 & 2.53 & 38.4 & \multicolumn{2}{|c|}{$20 \mathrm{KKD}$} & 03.57 \\
\hline 6 & 55 & $2011 / 12 / 10.21$ & $2011 / 12 / 10: 32$ & 11.6 & 124 & 3.42 & 24.2 & \multicolumn{2}{|c|}{16 Waste 8} & $08: 29$ \\
\hline 7 & 61 & $2011 / 12 / 10.23$ & 2011/12/1 0:34 & 11.0 & 129 & 2.65 & 21.7 & \multicolumn{2}{|c|}{$18 \mathrm{KKD}$} & $07: 20$ \\
\hline 8 & 38 & $2011 / 12 / 10: 24$ & $2011 / 12 / 10: 35$ & 11.6 & 132 & 2.94 & 26.1 & \multicolumn{2}{|c|}{$14 \mathrm{KKD}$} & $06: 46$ \\
\hline 9 & 54 & $2011 / 12 / 10: 24$ & $2011 / 12 / 10: 37$ & 12.7 & 139 & 3.01 & 20.6 & \multicolumn{2}{|c|}{$20 \mathrm{KCI}$} & $08: 45$ \\
\hline 10 & 59 & $2011 / 12 / 10: 24$ & $2011 / 12 / 10: 36$ & 11.3 & 128 & 3.36 & 24.6 & \multicolumn{2}{|c|}{16 Waste 8} & $08: 11$ \\
\hline 11 & 53 & $2011 / 12 / 10: 27$ & 2011/12/1 0:39 & 11.8 & 126 & 3.44 & 30.4 & \multicolumn{2}{|c|}{16 Waste 8} & $06: 47$ \\
\hline 12 & 60 & $2011 / 12 / 10: 28$ & 2011/12/1 0:41 & 13.0 & 130 & 2.76 & 12.7 & \multirow{2}{*}{\multicolumn{2}{|c|}{$\begin{array}{l}19 \mathrm{KKD} \\
14 \mathrm{KCI}\end{array}$}} & $13: 00$ \\
\hline 13 & 48 & $2011 / 12 / 10: 28$ & $2011 / 12 / 10: 39$ & 10.7 & 136 & 2.54 & 22.5 & & & $06: 47$ \\
\hline 14 & 47 & 2011/12/1 0:32 & 2011/12/1 0:45 & 12.1 & 132 & 3.12 & 23.7 & \multicolumn{2}{|c|}{$14 \mathrm{KKD}$} & 07.54 \\
\hline 15 & 46 & $2011 / 12 / 10: 33$ & $2011 / 12 / 10: 46$ & 13.0 & 139 & 3.14 & 22.3 & \multicolumn{2}{|c|}{$\begin{array}{l}19 \mathrm{KKD} \\
17 \mathrm{MLnn+n} 4\end{array}$} & $08: 28$ \\
\hline$\cdots$ & & 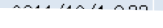 & $n n 11 / 1 n / 1 \cap \cdot 14$ & $11 n$ & 121 & $\cdots$ & 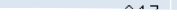 & \multicolumn{2}{|c|}{17 Whantn 4} & n..20 \\
\hline 8075 & 50 & 2011/12/8 18:11 & $2011 / 12 / 8 \mid \varangle: \angle<$ & 10.0 & 122 & 2.91 & 21.3 & \multicolumn{2}{|c|}{$14 \mathrm{KWI}$} & U8:12 \\
\hline 8076 & 63 & $2011 / 12 / 818: 14$ & $2011 / 12 / 818: 25$ & 10.7 & 118 & 2.88 & 25.5 & \multicolumn{2}{|c|}{$14 \mathrm{KCI}$} & $06: 46$ \\
\hline 8077 & 47 & $2011 / 12 / 8$ 18:17 & $2011 / 12 / 818: 27$ & 10.5 & 144 & 2.1 & 19.4 & \multicolumn{2}{|c|}{$16 \mathrm{KKD}$} & $06: 30$ \\
\hline 8078 & 64 & $2011 / 12 / 8$ 18:18 & $2011 / 12 / 818: 33$ & 14.4 & 128 & 4.16 & 24.6 & \multicolumn{2}{|c|}{15 Waste 8} & 10:10 \\
\hline 8079 & 49 & $2011 / 12 / 818: 22$ & $2011 / 12 / 818: 33$ & 10.7 & 120 & 2.54 & 20.0 & \multicolumn{2}{|c|}{$20 \mathrm{KKD}$} & $07: 37$ \\
\hline 8080 & 56 & $2011 / 12 / 818: 27$ & $2011 / 12 / 818: 39$ & 12.4 & 125 & 2.94 & 20.8 & \multicolumn{2}{|c|}{$20 \mathrm{KCI}$} & $08: 28$ \\
\hline 8081 & 52 & $2011 / 12 / 818: 27$ & $2011 / 12 / 818: 38$ & 11.6 & 130 & 3.45 & 25.3 & \multirow{2}{*}{\multicolumn{2}{|c|}{$14 \mathrm{KKD}$}} & $08: 11$ \\
\hline mamn & m & 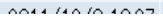 & 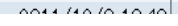 & $\ln n$ & $1 n n$ & $n \mathrm{mon}$ & $A=1$ & & & \\
\hline
\end{tabular}

Figure 2: The selected tracking transportation data extracted from the database of the information system 
Tan, Chinbat, Miwa and Takakuwa

Table 2: The excavation plan for one week

\begin{tabular}{c|r|r|r}
\hline Elevations and the No. of Mining Points & No. of Excavators & \multicolumn{1}{c|}{ Disposal Soil (tons) } & \multicolumn{1}{c}{ Ore (tons) } \\
\hline 1355 & 16 & 357,000 & 0 \\
\hline 1355 & 17 & 459,000 & 0 \\
\hline 1355 & 12 & 56,100 & 350,000 \\
\hline 1325 & 14 & 40,800 & 280,000 \\
\hline 1310 & 15 & 91,800 & 313,000 \\
\hline 1310 & 16 & 0 & 103,000 \\
\hline 1295 & 18 & 63,750 & 342,000 \\
\hline 1295 & 20 & 40,800 & 419,000 \\
\hline 1280 & 19 & 48,450 & 410,000 \\
\hline
\end{tabular}

Table 3: The selected GPS tracking data for excavation in a given week

\begin{tabular}{c|r|r|r|r|r|r|r|r}
\hline \multirow{2}{*}{$\begin{array}{c}\text { Excavator } \\
\text { No. }\end{array}$} & \multicolumn{2}{|c|}{ Ore Feeding Entrance A } & \multicolumn{2}{c|}{ Ore Feeding Entrance B } & \multicolumn{2}{c|}{ Disposal Hill (No. 4) } & \multicolumn{2}{c}{ Dis posal Hill (No. 8) } \\
\cline { 2 - 10 } & $\begin{array}{c}\text { Amount of } \\
\text { Excavation }(\mathrm{tn})\end{array}$ & $\begin{array}{c}\text { Distance } \\
(\mathrm{km})\end{array}$ & $\begin{array}{c}\text { Amount of } \\
\text { Excavation }(\mathrm{tn})\end{array}$ & $\begin{array}{c}\text { Distance } \\
(\mathrm{km})\end{array}$ & $\begin{array}{c}\text { Amount of } \\
\text { Excavation }(\mathrm{tn})\end{array}$ & $\begin{array}{c}\text { Distance } \\
(\mathrm{km})\end{array}$ & $\begin{array}{c}\text { Amount of } \\
\text { Excavation }(\mathrm{tn})\end{array}$ & $\begin{array}{c}\text { Distance } \\
(\mathrm{km})\end{array}$ \\
\hline $\mathbf{1 2}$ & 76519 & 2.14 & 8548 & 1.58 & 0 & 2.5 & 0 & 2.28 \\
\hline $\mathbf{1 4}$ & 121375 & 3.309 & 25542 & 2.54 & 0 & 1.51 & 7681 & 3.85 \\
\hline $\mathbf{1 5}$ & 5965 & 2.84 & 1686 & 3.25 & 0 & 1.39 & 108919 & 4.11 \\
\hline $\mathbf{1 6}$ & 45329 & 2.21 & 16235 & 2.62 & 120 & 1.38 & 48769 & 3.42 \\
\hline $\mathbf{1 7}$ & 126 & 2.23 & 0 & 2.62 & 146485 & 2.4 & 16796 & 2.28 \\
\hline $\mathbf{1 8}$ & 99590 & 2.65 & 14374 & 3.08 & 0 & 1.51 & 9809 & 3.85 \\
\hline $\mathbf{1 9}$ & 68223 & 3.22 & 22192 & 3.64 & 0 & 1.58 & 36398 & 4.2 \\
\hline $\mathbf{2 0}$ & 64241 & 2.55 & 23725 & 2.92 & 0 & 1.5 & 47635 & 3.72 \\
\hline
\end{tabular}

(Note: The Distance indicates the distance between the specific excavator.)

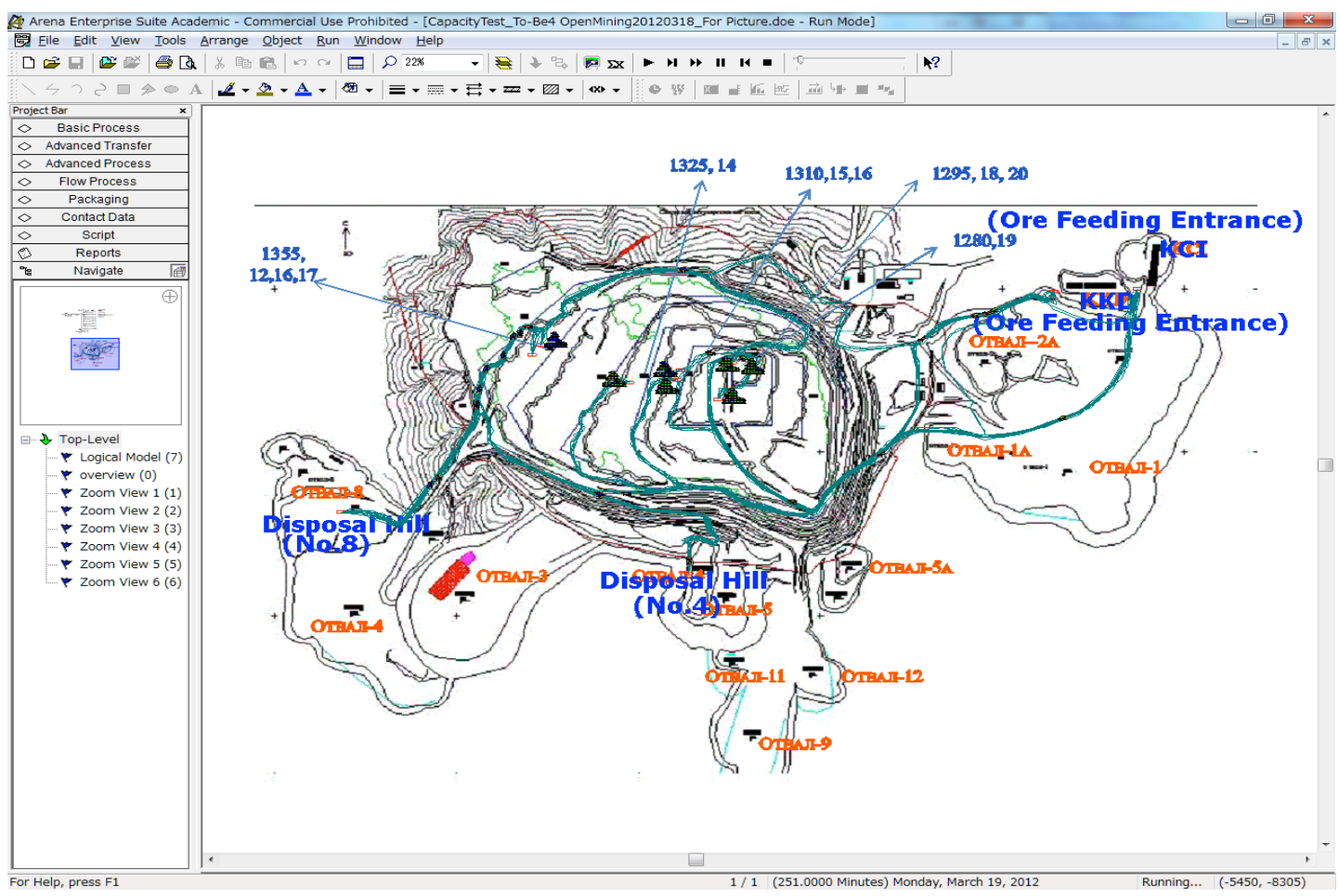

Figure 3: Animation of the As-Is model 


\subsection{The Results of Execution and Analysis of the As-Is Model}

After the As-Is model is built, validation of the model is accomplished through an interactive process between the company staff and the modeler; this interactive process compares the model's output with the real GPS tracking data. After confirming the reliability of the model, the simulation model is performed, and the results are analyzed. Table 4 shows the average execution results at the $95 \%$ confidence interval. The simulation is executed for a total of 30 replications.

The results in Table 4 demonstrate that the As-Is model was successful in transporting all of the planned volume by trucks within the specified amount of time; however, the scheduled utilization of the trucks was low $(71.2 \%)$. These scenario results imply that an excess number of trucks were prepared compared to the amount of planned work. As previously demonstrated by many other studies, the transportation of materials represents approximately 50 percent of the operating cost of an open pit mine (Alarie and Gamache 2002; Ercelebi and Bascetin 2009). In the case of company "A", a dump truck with a loading capacity of 130 tons uses significant quantities of gasoline. Considering the cost from the perspective of operations management, let us now focus on the number of trucks to be operated in the designated open pit, and let us perform this analysis based on a concrete mining plan. OptQuest is used to determine the best value for one or multiple objective functions (Kleijnen and Wan 2007).

Table 4: The execution result of the As-Is model

\begin{tabular}{|c|c|c|c|}
\hline \multicolumn{2}{|l|}{ Obervation Intervals } & \multicolumn{2}{|c|}{$\stackrel{\mathrm{Avg}}{5 \% \mathrm{CL}} \longrightarrow \mathrm{Max}$} \\
\hline Performance Indicators & As-Is & & His toric Value \\
\hline Expected Excavation Plan for Ore (tons) & \multicolumn{3}{|c|}{593,670} \\
\hline Expected Excavation Plan for Soil (tons) & \multicolumn{3}{|c|}{422,612} \\
\hline $\begin{array}{l}\text { The Length of Simulation / Total Time Taken } \\
\text { to Complete the Expected Excavation Plan (min.) }\end{array}$ & 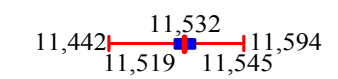 & & 11,502 \\
\hline Total Weight of the Transported Ore (tons) & & & 593,670 \\
\hline Total Weight of the Transported Soil (tons) & 422 & & 422,612 \\
\hline Average Weight per Transportation (tons) & $0 \longmapsto \frac{122}{122122} 152$ & & 122 \\
\hline Number of Transportations (round trips) & $\begin{array}{r}8,347181 \\
8,347 \\
8,3478,347\end{array}$ & & 8,347 \\
\hline Average Transportation Time Spent in a Single Trip (min.) & 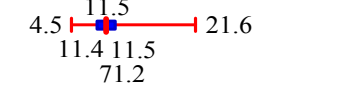 & & 11.8 \\
\hline Average Truck Scheduled Utilization (\%) & $0 \longmapsto 70.8 \quad 71.795 .8$ & & Not available \\
\hline
\end{tabular}

To use OptQuest, the appropriate objective and a series of constraints must first be determined. In this optimization problem, the objective is to minimize the cost of the trucks (the transportation cost); the planned excavation (ore: 593,670 tons, waste soil: 422,612 tons) must be performed within a specified time (in this case, 11,520 minutes). Thus, the optimization model in OptQuest is described as follows:

\section{Minimize:}

The number of trucks $(N T)$

\section{Subject to:}
(1) $1 \leqq N T \leqq 24$;
(2) $O_{t} \geqq 593,670$ tons 
(3) $S_{t} \geqq 422,612$ tons

(4) $T_{s} \leqq 11,520$ minutes

where

$N T$ : number of trucks,

$O_{t}:$ total amount of transported ore,

$S_{t}:$ total amount of transported waste soil,

$T_{s}$ : length of time of simulation run.

The completed optimal solution for this model was determined. In contrast to the current number of trucks, which is 24 in the As-Is model, the optimal number obtained by OptQuest is 19.

\subsection{The Scenarios and the To-Be Model}

After the optimal number of trucks was obtained from OptQuest, the To-Be model was built and executed to include the modified logic with respect to the number of trucks. Then, by varying the number of trucks from 12 to 25 , additional simulation experiments were executed to examine the relationship between the mined volume and the track utilization. Figure 4 shows the results of the sensitivity analysis.

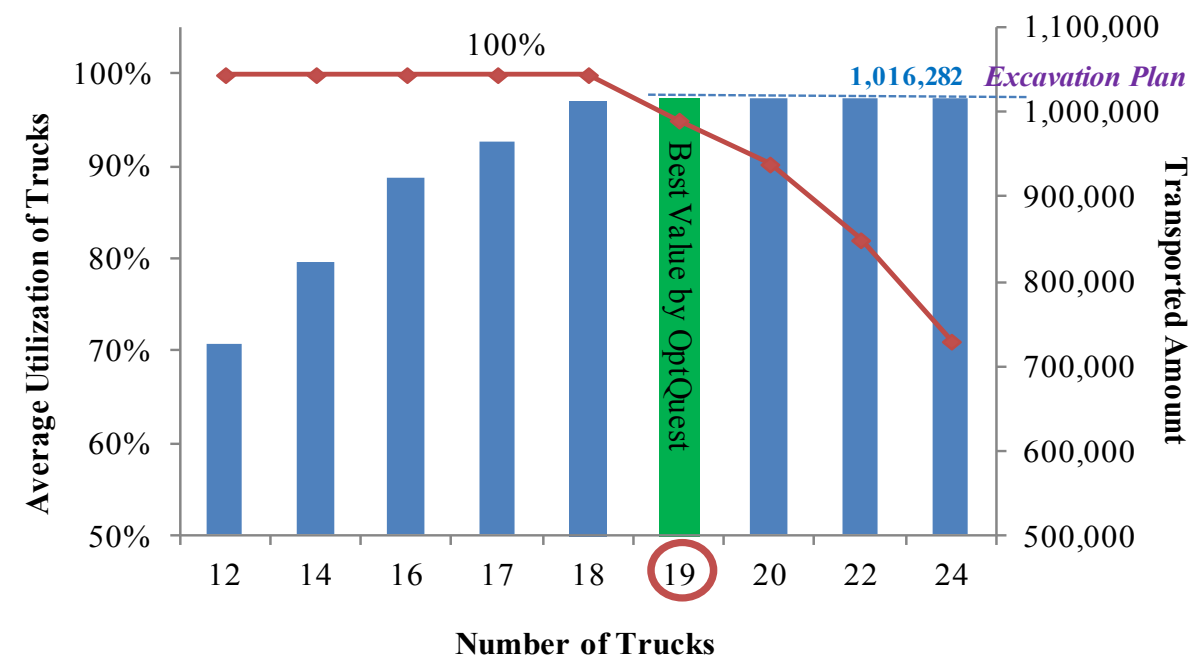

Figure 4: The sensitivity analysis of truck utilization and transported excavation as a function of the number of trucks.

\subsection{An Estimation of the Maximum Mining Capacity}

Another important objective of this work is to estimate the maximum mining capacity. As previously mentioned, knowledge of the maximum capacity of the open pit is also significant for planning the production of the enrichment plant. In this study, the maximum mining capacity is considered to be the achievement under the conditions of full operation with maximum utilization efficiency for the current facilities. Table 1 shows the machines and human resources that are currently held by company "A." To estimate the mining capacity of the open pit, it is necessary to construct another simulation model, called the To-Be (Capacity Test) model, which will work as the foundation for capacity testing, which is based on the To-Be model.

Before the To-Be (Capacity Test) model can be constructed, several preparatory processes must be performed. One of the most important processes is referred to as the process of entity generation. Similar to the As-Is and To-Be models, in the revised To-Be model (the Capacity Test), the ore and soil entities are also used. Additionally, the attribute of weight with a value of one ton is assigned to each of these entities. As previously mentioned, in this open pit mine, the contents of copper and molybdenum vary de- 
pending on the altitude of the mining points. Thus, to simplify the problem, we make the assumption that the mineral content and the ratio between the ore and soil contained in the new model have the same values as those in the To-Be and the As-Is models.

Although there are many approaches for entity generation, in this study, the entities in the To-Be $(\mathrm{Ca}-$ pacity Test) model are generated using the following processes:

1. The observation and analysis of the realistic output or the historical data, followed by the calculation of the ratio of ore and soil contained at each mining point.

2. The observation and analysis of the realistic output or the historical data at each excavator for the calculation of the rate to each destination by the mining points.

3. The collective generation of the entities, followed by the classification and assignment of the entities to the system according to the rates (the percentages) obtained using the two steps mentioned above.

As shown in Figure 1, in the mining system of company "A", an explosion process is held once every Friday based on the plan. During the rest of the week, the dump trucks then focus on transporting the ore and the soil between the designated mining points and either the enrichment plant or the disposal hills. All of the excavation planning for both the ore and the soil must be finished within the stipulated time. In this context, if the execution time length of the simulation is fixed as a constant, then the maximum number of entities entering the system can be considered to be the maximum mining capacity of the open pit for all of the running scenarios that satisfy the condition that the number of entities entering the system is equal to the number of entities leaving the system. Even if the number of entities entering the system exceeds the mining capacity, i.e., the trucks are already operating at full capacity (the utilization of each truck is at $100 \%$ ), the excess entities (the ore and soil) will not proceed and cannot be detached from the system.

Based on the historical transportation data on the trucks and an excavation plan with a period of eight days, the maximum mining capacity of company " $A$ " over eight days (or 11,520 minutes) can be estimated.

In this study, OptQuest is adopted once more to estimate the maximum mining capacity. The optimization model in OptQuest is described as follows:

\section{Maximize:}

The entity number sent to the system $\left(N_{e}\right)$

\section{Subject to:}

(1) $N_{o}=N_{e}$

(2) $T_{s}=11,520$ minutes

where

$N_{e}$ : entity number sent to the system (which is equal to the Expected Excavation Plan),

$N_{o}$ entity number exiting the system (which is equal to the Total Transported Amount), and

$T_{s}$ : length of time of the simulation run.

The To-Be (Capacity Test) model took approximately 20 minutes to run once in OptQuest. Finally, OptQuest determined a completed optimal solution of $N_{e}=1,502,334$. According to this result, the maximum mining capacity for eight days in this open pit can be estimated to be $1,502,334$ tons. Additionally, the simulation model is used to validate the solution provided by OptQuest. In addition, the maximum mining capacity found through the analysis was given to company "A", and the company managers found our results agreeable; that is, they found the suggested capacity to be reasonable and convincing. A portion of the truck dispatching control table output by the To-Be (Capacity Test) model, which can be used to achieve the maximum mining capacity of 1,502,334 tons, is shown in Figure 5. 
Tan, Chinbat, Miwa and Takakuwa

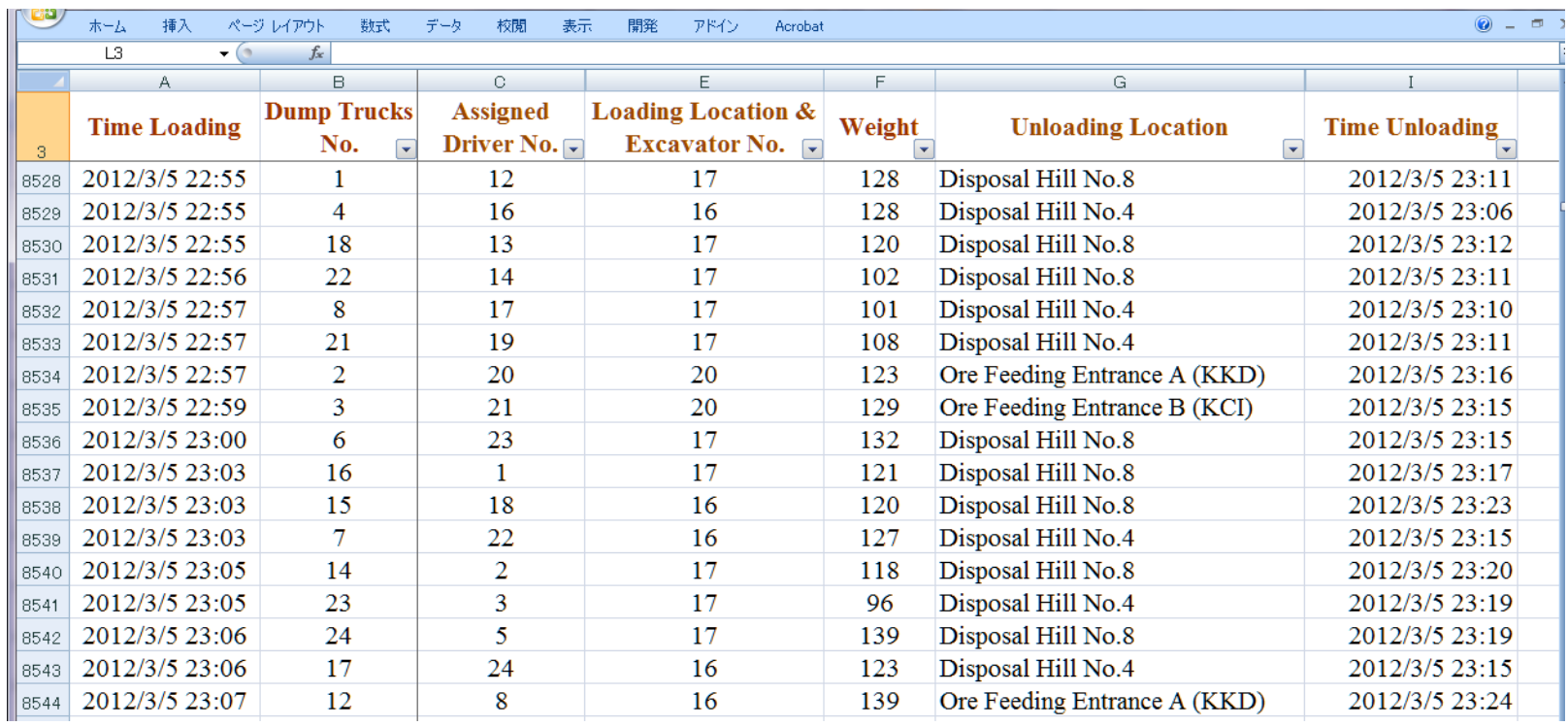

Figure 5: Truck dispatching in the control table output from the To-Be (Capacity Test) model (Partial)

\section{CONCLUSIONS}

A computer simulation technique was applied to support operations management in a large-scale open pit copper mine where a significant amount of dump trucks were operated to convey ore from the mining site to the entrance of a successful refinery. A simulation model was constructed and executed by utilizing GPS tracking data on dump truck movement. Analysis on the number of dump trucks was performed as an application based on the constructed As-Is model. It was found that an equivalent performance could be achieved with fewer dump trucks than the number currently operated. Additionally, a simulation was used to create a truck dispatch control table to meet the maximum mining capacity. Simulations can help mining project managers understand the behavior of the system, allowing for the optimization of a system through various strategies by providing visual and dynamic descriptions.

\section{ACKNOWLEDGMENTS}

This research was supported by the Grant-in-Aid for the Asian CORE Program "Manufacturing and Environmental Management in East Asia" and the Grant-in-Aid for Scientific Research (B) (No. 233301216) "Mongolian Mining Projects and Global Logistics" of the Japan Society for the Promotion of Science (JSPS). This work was conducted jointly by the National University of Mongolia and Nagoya University. The sample data used in this paper for representing the mining operations are fictitious.

\section{REFERENCES}

Alarie, S. and M. Gamache, 2002. "Overview of solution strategies used in truck dispatching systems for open pit mines." International Journal of Surface Mining, Reclamation and Environment 16:59-76.

Bauer, A., and P. N. Calder. 1973. "Planning Open pit Mining Operations Using Simulation." In APCOM 1973, 273-298. Johannesburg: South Africa Institute of Mining and Metallurgy.

Biles, W. E. and J. K. Bilbrey. 2004. "Integration of Simulation and Geographic Information Systems: Modeling Traffic Flow on Inland Waterways." In Proceedings of the 2004 Winter Simulation Conference, ed. R. G. Ingalls, M. D. Rossetti, J. S. Smith, and H. A. Peters, 1392-1398. Piscataway, New Jersey: Institute of Electrical and Electronics Engineers, Inc. 
Boland, N., I. Dumitrescu, G. Froyland, and A. M. Gleixner. 2009. "LP-based Disaggregation Approaches to Solving the Open pit Mining Production Scheduling Problem With Block Processing Selectivity." Computers \& Operations Research 36: 1064-1089.

Burt, C., L. Caccetta, S. Hill, and P. Welgama. 2005. "Models for Mining Equipment Selection." In Proceedings of MODSIM 2005 International Congress on Modelling and Simulation, ed. Zerger, A., and R. M. Argent, 170-176.

Chinbat, U., and S. Takakuwa. 2008. "Using Operation Process Simulation for a Six Sigma Project of Mining and Iron Production Factory." In Proceedings of the 2008 Winter Simulation Conference, ed. S. J. Mason, R. R. Hill, L. Monch, O. Rose, T. Jefferson, And J. W. Fowler, 2431-2438. Piscataway, New Jersey: Institute of Electrical and Electronics Engineers, Inc.

Chinbat, U., and S. Takakuwa. 2009. "Using Simulation Analysis for Mining Project Risk Management." In Proceedings of the 2009 Winter Simulation Conference, Edited by M. D. Rossetti, R. R. Hill, B. Johansson, A. Dunkin and R. G. Ingalls, 2612-2623. Piscataway, New Jersey: Institute of Electrical and Electronics Engineers, Inc.

Ercelebi, S. G. and A. Bascetin. 2009. "Optimization of shovel-truck system for surface mining." Journal of The Southern African Institute of Mining and Metallurgy 109:433-439.

Fioroni, M. M., L. A. G. Franzese, T. J. Bianchi, L. Ezawa, L. R. Pinto, de Miranda, and J. Gilberto. 2008. "Concurrent Simulation and Optimization Models for Mining Planning." In Proceedings of the 2008 on Winter Simulation Conference, ed. S. J. Mason, R. R. Hill, L. Moench, O. Rose, 759-767. Piscataway, New Jersey: Institute of Electrical and Electronics Engineers, Inc.

Kazakidis, V. N., and M. Scoble. 2003. "Planning for Flexibility in Underground Mine Production Systems. Mining Engineering." Available via http://www.highbeam.com/doc/1P3-404117771.html [accessed March 1, 2011].

Kelton, D., R. Sadowski, and N. B. Swets. 2010. Simulation with Arena. 5th Edition. New York: McGraw-Hill, Inc.

Kleijnen, J. P. C., and J. Wan. 2007. "Optimization of simulated systems: OptQuest and alternatives." Simulation Modelling Practice and Theory 15: 354-362.

Kolojna, B., D. R. Kalasky, and J. M. Mutmansky. 1993. "Optimization of dispatching criteria for open pit truck haulage system design using multiple comparisons with the best and common random numbers." In Proceedings of the 1993 Winter Simulation Conference, ed. G. W. Evans, M. Mollaghasemi,. E.C. Russell,. W.E. Biles. 393-401. Piscataway, New Jersey: Institute of Electrical and Electronics Engineers, Inc.

Miwa. K., and S. Takakuwa. 2011. "Operations modeling and analysis of an underground coal mine." In Proceedings of the 2011 Winter Simulation Conference, ed. S. Jain, R.R. Creasey, J. Himmelspach, K.P. White, and M. Fu, 1685-1695. Piscataway, New Jersey: Institute of Electrical and Electronics Engineers, Inc.

Neonen, L. K., P. W. U. Graefe, and A. W. Chan. 1981. "Interactive computer model for truck/shovel operations in an open pit mine." In Proceedings of the 1981 Winter Simulation Conference, ed. T.I. Oren, C.M. Delfosse, C.M. Shub, 133-139. Piscataway, New Jersey: Institute of Electrical and Electronics Engineers, Inc.

Newman, A., E. M. Rubio, R. Caro, A. Weintraub, and K. Eurek. 2010. "A Review of Operations Research in Mine Planning." Interfaces 40(3): 222-245.

Navon, R. and Y. Shpatnitsky. 2005. "A Model for Automated Monitoring of Road Construction." Construction Management and Economics, 239, 941-951.

Qing-Xia, Y. 1982. "Computer simulation of drill-rig/shovel operations in open pit mines." In Proceedings of the 1982 Winter Simulation Conference, ed. H. J. Highland, Y. W. Chao, and O. S. Madrigal, 463-468. Piscataway, New Jersey: Institute of Electrical and Electronics Engineers, Inc.

Ramazan, S. and R. Dimitrakopoulos. 2004. "Recent applications of operations research and efficient MIP formulations in open pit mining." SME Transactions 316:73-78. 
Shannon, R. E. 1998. "Introduction to the Art and Science of Simulation." In Proceedings of the 1998 Winter Simulation Conference, Edited by D. J. Medeiros, E. F. Watson, J. S. Carson and M. S. Manivannan, 7-14. Piscataway, New Jersey: Institute of Electrical and Electronics Engineers, Inc.

Song, L., F. Ramos, and K. Arnold. 2008. "A Framework for Real-Time Simulation Of Heavy Construction Operations." In Proceedings of the 2008 Winter Simulation Conference, ed. S. J. Mason, R. R. Hill, L. Monch, O. Rose, T. Jefferson, And J. W. Fowler, 2387-2395. Piscataway, New Jersey: Institute of Electrical and Electronics Engineers, Inc.

Subtil, R. F., D. M. Silva, and J. C. Alves. 2011. "A Practical Approach to Truck Dispatch for Open pit Mines." $35^{\text {Th }}$ APCOM symposium, 24-30.

\section{AUTHOR BIOGRAPHIES}

YIFEI TAN is a Junior Associate Professor on the Faculty of Commerce at Chuo Gakuin University in Japan. He received a B.A. Degree in 2001 from Southwest Jiaotong University in China and a M.Sc. Degree in Economics from Nagoya University in Japan in 2004. He received his Ph.D. from the Graduate School of Economics and Business Administration at Nagoya University in 2008. His research interests include business process management, management information systems, and the optimization of manufacturing and logistics systems. His current research focuses on the use of simulations for evaluating the business impact of information systems. His email address is yftan@cc.cgu.ac.jp.

UNDRAM CHINBAT is a Professor and the head of the Management Faculty at the School of Economic Studies at the National University of Mongolia. She received her B.A. in 2003 and M.B.A. in 2004 from the International University of America, London campus, UK. She obtained a Ph.D. in Economics from the Graduate School of Economics and Business Administration of Nagoya University in Japan. Her research interests include project management, risk management, and mining business management. Her current research focuses on the use of simulation analysis for mining process optimization. Her email address is undram@ses.edu.mn.

KANNA MIWA is an Associate Professor on the Faculty of Commerce at the Nagoya Gakuin University in Japan. She received her B.Sc. and M.Sc. degrees in Economics from Nagoya University in 2000 and 2003, respectively. She received her Ph.D. from the Graduate School of Economics and Business Administration at Nagoya University in 2006. Her research interests include the optimization of logistics, supply chains, and manufacturing systems. Her email is kmiwa@ngu.ac.jp.

SOEMON TAKAKUWA is a Professor at the Graduate School of Economics and Business Administration at Nagoya University in Japan. He received his B.Sc. and M.Sc. degrees in industrial engineering from the Nagoya Institute of Technology in 1975 and from the Tokyo Institute of Technology in 1977, respectively. His Ph.D. is in industrial engineering from Pennsylvania State University. He holds a Doctorate of Economics from Nagoya University. His research interests include the optimization of manufacturing and logistics systems and simulation analysis of these systems, which include hospitals. He has prepared the Japanese editions of both Introduction to simulation using SIMAN and Simulation with Are$n a$. He has been serving concurrently on the senior staff of the Department of Hospital Management Strategy and Planning at Nagoya University Hospital. His email address is takakuwa@soec.nagoyau.ac.jp. 